\title{
The Bridge between Emotion and Crime
}

\author{
Murat Senavci \\ Dept. of Forensic Medicine \\ Aydin Adnan Menderes University, School of Medicine, Aydin, Turkey \\ Email: oerel@adu.edu.tr \\ Ozlem Erel (Corresponding author) \\ Dept. of Forensic Medicine \\ Aydin Adnan Menderes University, School of Medicine, Aydin, Turkey \\ Email: oerel@adu.edu.tr \\ Serpil Demirag \\ Dept. of Family Medicine \\ Aydin Adnan Menderes University, School of Medicine, Aydin, Turkey
}

\begin{abstract}
The definition of law is broadly defined as the whole of the regulations that organize the general society and that determine the sanction power of the government. Although law and science have a wide range of interests, it is necessary to establish a bridge between law and science in order to preserve the greatest gains of humanity such as life and freedom. Law is regulated and based on an old theory consisting beliefs and customs rather than neuroscience. In this article, we try to make a brief summary about where they connect and separate.
\end{abstract}

Keywords: Law, neuroscience, justice, emotion

\section{Special Issue of Health Sciences}

DOI: $10.7176 / \mathrm{JSTR} / 6-03-32$

\section{INTRODUCTION}

The definition of law is broadly defined as the whole of the regulations that organize the general society and determine the sanction power of the government (1). Although law and science have a wide range of interests, it is necessary to establish a bridge between law and science in order to preserve the greatest gains of humanity such as life and freedom. Law is regulated and based on an old theory consisting beliefs and customs rather than neuroscience.

\section{Law and Science}

According to the latest data, there are 206 countries in the world (2). There are social, moral and legal rules on where and when the emotions and behaviors are acceptable and how they should be expressed in societies. Although habits or traditions can vary from one country to another, some are universal, such as celebrating special dates. Each country has social rules for their own feelings and behaviors and these rules are established by existing legal systems. For example in Turkey $(3,4,5,6,7,8)$, the purposes of the Criminal Code (Turkish Criminal Code-TCC) are "to protect the public peace, individual rights and freedoms; to supply public order and security; to rule the law; to maintain public health and the environment and to prevent crime".

The main function expected from law is to ensure the justice. Legal systems in many countries, including Turkey, are expected to separate entities from emotions and logic (9). Therefore, in many brutally committed murders; the defendants generally stated that they were prisoners of anger and they lost their will. Law is regulated and based on an old theory based on beliefs and customs rather than neuroscience, but is it appropriate?

In this article, we aimed to make a brief summary about where law and neuroscience connect and separate. Our second aim was to call attention to this important issue. 


\section{Emotional Instant Murders}

According to Turkish codes $(10,11)$, one will not be partially liable for the damage he/she does, if they are under control of severe anger/pain during the commitment of crime. Although there is debate about this issue today; the intentional murders are still accepted as worse than the anger murders according to our laws. In other words, anger causes people incapable to perform their actions legally and therefore, to be held partly responsible for their actions.

Anger has a multidimensional structure. Psychological, cognitive, phenomenological and behavioral dimensions characterize the variables (12). All emotions are the product of the mind as much as the objects and events that trigger them, and cause similar changes in the body such as other emotions, like anger (13). For example; conditions such as increased heartbeat and flushing during anger can occur likewise during bouts of happiness. However, very few of the murders occur during happiness and sadness, and in this case, the law do not treat seizures as an alleviating factor. There seems no penal reduction for other emotional conditions such as happiness and sadness (14).

Kuppens et. al. created anger under laboratory conditions (15). They witnessed swearing, threatening, punching the table, leaving the room, crying, trying to solve the existing problem, and even smiling, instead of killing. The idea that anger triggers out-of-control murder is at best controversial. In order to be regarded as responsible for our actions, it is not enough to carry out an act (material element) that is in conformity with the real type of crime (legal element), contrary to the legal order (element of unlawfulness). In addition to these objective elements, the existence of a subjective element (spiritual element) is sought (16). Emotions are seen as quick and automatically triggered reactions. The human mind is also considered as the "battlefield of logic and emotion"; so it is said that when enough cognitive discipline is provided, emotions can control the behavior (17). It is assumed that they interfere with the behavioral preferences and therefore prevent the person from being fully accountable for the event. But, is it the case? Emotions are not the forces that capture us. You are actually "your brain", and the reason for the success is the predictive power of your brain. The idea of not being in control seems to be a twostage process, such as decision-making and movement (18). Does that thinking and feeling occur separately in the brain? Emotions, the brain and the mind create a natural environment within the organism to respond appropriately or to adapt (19). We study not only the existence of the object, but also its relationship with other objects and its connection to the past. In these conditions, the means of emotions are self-evaluated and the tools of the conscious mind are simultaneously evaluated through thought. We can even adapt our emotional response. In fact, one of the main objectives in our educational development is to create a non-automatic appraisal phase between the emotive object and the emotional responses. By doing so, we are trying to shape our natural emotional responses and adapt them to the requirements of our culture. Emotions can work in different environments (19). Even when the emotional response occurs unintentionally, emotion is an indication that the organism is assessing the situation. It is not very important that the evaluation is done unconsciously. An instant tantrum may sometimes seem to us not to be controlled (20). When examining the anamnesis of the murder criminals, "I committed a moment of anger with murder", "I accidentally did not want to" seem as the reasons of such crimes (20). Anger and other emotions are literally not a single automatic response, but a collection of examples (21). This applies to all categories of true emotion, cognition, perception and other mental events. You may feel that there is a slow and more deliberate process alongside a fast and intuitive process in your brain; the first of these two processes may seem more emotional and the latter more rational, but this thought is not defensible in neuroscience and behavioral basis. Sometimes your control network plays a big role in the editing process, sometimes it plays a smaller role. However, it is always in the process and may not be emotional when it plays small roles (21). So, why does the fiction that brain separates emotion and cognition still exist? Many psychological experiments are carried out unconsciously based on the same fiction. In particular, decisions are assumed to be made within the same sensorimotor circuits that are responsible for planning and executing the associated actions (22). The legal system confuses whether the brain plays any role in controlling behavior or not. Here, the paths of science and law are separated. Law defines deliberate choice, i.e. free will, as having control of self-thoughts and actions. Neural network cannot distinguish between the ability to choose, and the objective choice experience (23). These two phenomena are not the same in the brain. Scientists are still trying to understand how the brain forms the experience of having control. However, one thing is certain: "to call a moment without control awareness as emotion" has no scientific basis. Our movements work with the decision-making mechanisms of our brains (23). Decision-making mechanisms occur with the help of many interconnected mechanisms in our brain. As the arousal symptoms and internal conditions are similar to many different emotions, it is sometimes possible to confuse them when experienced in unclear, unusual situations (23). However, this condition is also valid for memories and thoughts as well as emotions. As 
a result, we can conclude that: the more you control your thoughts, perceptions or memories, the more you control your emotions.

In conclusion, we may say that events that seem happening automatically may not be completely out of control and may not be emotional. When an emotion is formed by brain, the amount of control given is the same as the amount of control when a thought or a memory is constructed. No matter how automatic it feels, most instances of anger don't cause murder. Anger can also emerge over a long period of time. Therefore, there is nothing inherently automatic about anger. Regardless of whether the issue is emotional or cognitional, people are relatively more responsible for their actions if they are intentional. Besides, when regarding of the types of emotional patterns that change throughout humanity, it should be remembered that culture can always say the last word. These categories should not be confused with physical and biological categories separated by deep boundaries in nature.

\section{REFERENCES}

1- Turkish Dictionary. (accessed from http://sozluk.gov.tr/ on August 29th, 2019)

2- Lists of Countries. (accessed from https://tr.wikipedia.org/wiki/ülkeler_listesi on August 29th, 2019)

3- Turkish Criminal Code (In Turkish). https://www.mevzuat.gov.tr/MevzuatMetin/1.5.5237.pdf.

4- Sahin E. The purposes of the Criminal Code. History of criminal proceedings, TAAD, 2014;5(18):349-385 (in Turkish).

5- The purposes of the Criminal Code. Toroslu N, General Section of Criminal Law, Ankara; 2014 (In Turkish).

6- Toroslu N, Toroslu H The purposes of the Criminal Code. General Section of Criminal Law, Savas Publications, Ankara; 2018 (In Turkish).

7- Toroslu H. The purposes of the Criminal Code. Capability of Attribution in Criminal Law, Ankara, 2015 (In Turkish).

8- Artuk ME, Gokcen A, Alasahin ME, Cakır K. The purposes of the Criminal Code. General Section of Criminal Law, Ankara, 2017 (In Turkish).

9- Aldanmaz O. Resurrection of Emotions in Law (In Turkish).. Electronic Journal of Social Sciences, 2014;13(49):182-202

10-Dan M. Kahan, Martha C. Nussbaum, Columbia Law Review, Two Conceptions of Emotion in Criminal Law, Faculty Scholarship Series, 1996;96(2):269-374.

11-Percy EJ, Hoffman JL, Sherman SJ. Sticky Metaphors and the Persistence of the Traditional Voluntary Manslaughter Doctrine, 2011;44(2): 393-394.

12-Eckhardt C, Norlander B, Deffenbacher J. The assesment of anger and hostility: A critical review. Aggression and Violent Behavior, 2004;9: 17-43.

13-Kreibig, SD. Autonomic nervous system activity in emotion: A review. Biological Psychology, 2010;84: 394-421.

14-Number 62-2. Turkish Criminal Code (In Turkish) (Accessed from https://www.tckmadde.com/62-2/ on August 28th,2019).

15-Kuppens P, Mechelen IV, Smits DJM, Boeck PD, Ceulemans E. Individual differences in patterns of appraisal andanger experience. Cognition And Emotion, 2007; 21(4): 689-713. 
16-Ozden SY. Legal Elements (In Turkish). In Forensic Psychiatry, Nobel Academic Publishing Distribution, 2015;2: 63.

17- Barret, LF. Battlefield of logic and emotion. How Emotions Are Made: The Secret Life of the Brain (In Turkish), 2018;1: 316,317.

18-Wople N, Rowe, JB. Beyond the "urge to move": objective measures for the study of agency in the post-Libet era. Front Hum Neurosci 2014;8: 450.

19- Damassio A. The emotional response (In Turkish). Looking for Spinoza, Joy, Sorrow and Feeling Pain. Translated by: Kumral E, Cetiner I. 2018;1: 56-57.

20- Records of Department of Forensic Medicine, Adnan Menderes University, School of Medicine. Unpublished Data.

21-Barrett LF, Tugade MM. Individual Differences in Working Memory Capacity and Dual-process Theories of The Mind. Psychol Bull, 2004; 130(4): 553-573.

22-Cisek P, Kalaska JF. Neural Mechanisms for Interacting with a World Full of Action Choices. Annu Rev Neurosci, 2010; 33:269-98.

23-Graziano M. Consciousness and the Social Brain, Oxford University Press, 2013:159-167. 